\title{
Adding MERGE Sequence to Routine MRI Examination of the Knee: Is it Valuable?
}

\author{
SUZAN OMAR, M.D. and ABDELGHANY M. MOTAWEA, M.D. \\ The Department of Radiology, Faculty of Medicine, Menofia University
}

\begin{abstract}
Background: Osteoarthritis is a leading cause of disability which has major implications in elderly and public health. Early detection is critical for understanding the disease progression which can contribute in development of new treatment strategies to stop or slow its progression. MRI has excellent soft tissue contrast and advanced techniques have improved its ability to evaluate cartilage morphology and macromolecular changes.
\end{abstract}

Aim of Study: To test the value of adding T2 MERGE sequence to the routine (MRI) protocol of the knee for early detection of cartilage changes around the knee.

Patients and Methods: We retrospectively evaluated the images of 107 patients (64 male and 43 female) age ranged between 23-52 years (mean 43.52) who underwent MRI examination of the knee at Menofia University Hospital between June 2019 and February 2020.

Results: Our study was a retrospective study done between June 2019 and Feb. 2020 on 107 patients. The patient's age ranged from 23 to 67 years with the mean age $45.6 \pm 12.7$ years. The study included 64 males and 43 females.

There was slight agreement between T2WI and surgical grading $(\kappa 0 / 172, p<0.001)$, while there was total agreement between $3 \mathrm{D}$ merge and surgical grading $(\kappa 1.00, p<0.001)$.

3D MERGE had $100 \%$ sensitivity, 100\% PPV and $100 \%$ overall accuracy compared to Arthroscopic findings.

Conclusion: Adding MERGE sequence to the routine protocol of knee MRI has improved sensitivity for detection of early cartilage lesions.

Key Words: Osteoarthritis $(O A)-$ Knee - MRI - 3D-MERGE (Multiple Echo Recombined Gradient Echo).

\section{Introduction}

OSTEOARTHRITIS (OA) is a leading cause of lower extremity disability among elderly. Its pathogenesis is based on changes in articular cartilage with progressive loss of its hyaline matrix and increase in water content [1-4].

Correspondence to: Dr. Suzan Omar, The Department of Radiology, Faculty of Medicine, Menofia University
A sensitive method for detecting structural and functional changes of cartilage in the early stages of $\mathrm{OA}$ is required for assessing the progression of disease and monitoring the response to therapy [5].

MRI is able to assess OA related morphological abnormalities with evaluation of cartilage thickness. It also can be helpful in detecting changes in biochemical composition of the cartilage in early stages $[\mathbf{6 , 7 , 8}]$.

Many Standard sequences such as T2-weighted and proton density-weighted spin-echo and turbo spin-echo sequences with and without fat suppression can detect cartilagenous defects [9].

Dedicated sequences for cartilage evaluation improve the reliability of MRI in early detection of cartilage abnormalities such as 3D spoiled gradient echo (SPGR) or 3D fast low-angle shot (FLASH) sequences with fat saturation and 3D double-echo steady-state (DESS) sequences, which showed sensitivity and specificity as high as $96 \%$ and $95 \%$, respectively [10,11].

These techniques provide $\mathrm{T} 2$ quantification of the cartilages, which can be a promising imaging biomarkers of osteoarthritis which can assess cartilage quality and susceptibility to injury with noninvasive way $[\mathbf{1 2 , 1 3 ]}$.

\footnotetext{
List of Abbreviations:

OA : Osteoarthritis.

MRI : Magnetic resonance imaging.

3D : 3 Dimensional.

MERGE : Multiple Echo Recombined Gradient Echo.

MEDIC : Multi-echo Data Image Combination.

DESS : Double Echo Steady State.

SPGR : Spoiled Gradient Recalled Acquisition.

FLASH : Fast Low Angle Shot.

PPV : Positive predictive value.

NPV : Negative predictive value.
} 
T2 mapping techniques can measure alterations in the water and collagen content of cartilage. It enables early detection of biochemical changes in cartilage degeneration before morphological changes are evident in early OA. It also can follow treatment response based on changes in $\mathrm{T} 2$ values [14].

Newly developed (MERGE/MEDIC/M-FFE) combination sequence is another MRI sequence useful in imaging of articular cartilage [15].

MERGE ("Multiple Echo Recombined Gradient Echo") is a spoiled T2* weighted sequence for spinal and musculoskeletal imaging developed by GE Healthcare. The corresponding Siemens sequence is called MEDIC ("Multi-Echo Data Image Combination"), while the Philips sequence is called M-FFE ("Merged Fast Field Echo"). These sequences are useful for both volumetric and $\mathrm{T} 2 *$ relaxation time analyses of cartilage [16].

This sequence eliminates the main limitations of other gradient-echo sequences such as chemical shift, low signal-to-noise ratio and image degradation due to susceptibility gradients. This is achieved by acquiring and combining multiple echoes with a high receiver bandwidth instead of using a single low band width echo [17].

Aim of study: This study was performed to test the value of adding T2 MERGE sequence to the routine (MRI) protocol of the knee for early detection of cartilage changes around the knee.

\section{Patients and Methods}

\section{Study population:}

We retrospectively evaluated the images of 107 patients (64 male and 43 female) age ranged between 23-52 years (mean 43.52) who underwent MRI examination of the knee at Menofia University Hospital between June 2019 and February 2020.

Inclusion criteria were patient who underwent both knee MRI and MRI arthroscopy of the knee.

Exclusion criteria were patient with rheumatoid arthritis or other inflammatory arthritis, bilateral advanced joint space narrowing, and children.

\section{MRI technique:}

The MRI was performed on GE Optima MR450w 1.5 T MR system:

- The 3D MERGE sequence was performed using the following imaging parameters: TR 500-950, TE5-20, FOV16, Slice thickness $2.4 \mathrm{~mm}$ (inter- slice gap 2mm) Flip angle $20^{\circ}$, matrix 256x224, Echo train length 4, band width 31.25. Number of slices about 30 . The image acquisition time was $4 \mathrm{~min}$ and $38 \mathrm{sec}$.

- Conventional sagittal T2-weighted fast spin echo (FSE) images was performed using the following imaging parameters: TR $8.24-9,57 \mathrm{~ms}$; TE 139 $141 \mathrm{~ms}$; FOV 140 x 140mm; image matrix 512 x 512; slice thickness, $3 \mathrm{~mm}$ (inter-slice gap, $0.3 \mathrm{~mm}$ ), flip angle $160^{\circ}$; slice number about 30 , and echo train length 24 . The image acquisition time was $4 \mathrm{~min}$ and $5 \mathrm{sec}$.

- Conventional axial T1 weighted FSE images was performed using the following imaging parameters: TR, 609-831ms, TE $10 \mathrm{~ms}$, FOV, $140 \mathrm{x}$ $140 \mathrm{~mm}$, image matrix $384 \times 320$, slice thickness $3 \mathrm{~mm}$ (inter-slice gap $1 \mathrm{~mm}$ ), flip angle $111^{\circ}$; slice number about 30 , and echo train length 3 . The image acquisition time was $3 \mathrm{~min}$ and $39 \mathrm{sec}$.

Surgical grading of cartilage Lesions: [17]

A 5 point scale grading system; modification of the system originally described by Outerbridge [17] used by the surgeons to categorize cartilage damage as follow:

- Grade 0, normal;

- Grade 1, softening or swelling;

- Grade 2, partial thickness defect;

- Grade 3, fissuring to the level of the subchondral bone; or

- Grade 4, exposed subchondral bone.

In the original Outerbridge classification system, grades 2 and 3 lesions are defined as fragmentation or fissuring with a diameter of less (grade 2) or more (grade 3 ) than 1 inch.

\section{Imaging evaluation and scoring system: [3]}

- Grade 0, normal thickness and signal intensity;

- Grade 1 , increased signal intensity without cartilage deformity or cartilage swelling

- Grades 2, partial thickness defect

- Grade 3, fissuring to the level of subchondral bone, less than $1 \mathrm{~cm}$ in width

- Grade 4, focal (more than $1 \mathrm{~cm}$ width) or diffuse complete loss of retropatellar cartilage with exposed bone.

The retropatellar cartilage (medial and lateral facets) was analyzed as a single entity. The highest grade of cartilage abnormality was used in cases of multiple retro-patellar cartilage defects. 


\section{Statistical analysis:}

Data were analyzed by SPSS statistical package version 23 (SPSS Inc. Released 2015. IBM SPSS statistics for windows, version 23.0, Armnok, NY: IBM Corp.). Cohen's $\kappa$ (or interrater classification) was run to determine the agreement between two surgical grading and each imaging technique. Two sided $p$-value was considered statistically significant.

\section{Kappa agreement:}

$-<0$ Less than chance agreement.

- 0.01-0.20 Slight agreement.

- 0.21-0.40 Fair agreement.

- 0.41-0.60 Moderate agreement.

- 0.61-0.80 Substantial agreement.

- 0.81-0.99 Almost perfect agreement.

\section{Results}

There were 107 patients (64 male and 43 female) studied with M/F ratio 1.48/1. Their ages ranged between 23-52 years (mean age 43.52).

The cause for performing MRI examination was knee trauma in 64 patients, knee swelling in 32 patients, continuous pain not responding to analgesic in 11 patients.
Most of studied patients in our study had lowgrade cartilage lesions. Surgery identified grade 0 $(n=50)$, grade $1(n=26)$, grade $2(n=8)$, grade 3 $(n=19)$, and grade $4(n=4)$. As most of the patients were young age and underwent knee MRI after trauma to evaluate Cruciate ligaments injury $(n=64)$.

Table (1) showed that There was slight agreement between T2WI and surgical grading $(\kappa 0 / 172$, $p<0.001$ ), while there was total agreement between $3 \mathrm{D}$ merge and surgical grading $(\kappa 1.00, p<0.001)$.

Routine T2WI sequence detected fifteen patients to have grade I cartilage lesion, fourteen patients had grade II lesion, six patients had grade 3 lesion and four patients had grade 4 lesion.

3D MERGE sequence detected twenty six patients to have grade I cartilage lesion, eight patients had grade 2, nineteen patients had grade 3 and four patients had grade 4 cartilage lesion.

Table (2) showed that T2WI had 33\% sensitivity, 100.0 positive predictive value (PPV), 57\% negative predictive value (NPV) and 64\% overall accuracy, while 3D MERGE had 100.0 sensitivity, $100.0 \%$ PPV and 100.0 overall accuracy in comparison to surgical findings.

Table (1): $p$-value and $\kappa$ agreement of used sequences with surgical findings.

\begin{tabular}{|c|c|c|c|c|c|c|}
\hline \multirow{2}{*}{ Image grading } & \multicolumn{5}{|c|}{ Surgical grading } & \multirow{2}{*}{$\begin{array}{c}\kappa \\
p \text {-value }\end{array}$} \\
\hline & $0(n=50)$ & $I(n=26)$ & II $(\mathrm{n}=8)$ & III $(n=19)$ & IV $(n=4)$ & \\
\hline \multicolumn{7}{|l|}{$T 2 W 1:$} \\
\hline Grade 0 & $50(100.0)$ & $18(69.2)$ & $0(0.0)$ & $0(0.0)$ & $0(0.0)$ & 0.172 \\
\hline Grade I & $0(0.0)$ & $8(30.8)$ & $7(87.5)$ & $0(0.0)$ & $0(0.0)$ & 0.002 \\
\hline Grade II & $0(0.0)$ & $0(0.0)$ & $1(12.5)$ & $13(68.4)$ & $0(0.0)$ & \\
\hline Grade III & $0(0.0)$ & $0(0.0)$ & $0(0.0)$ & $6(31.6)$ & $0(0.0)$ & \\
\hline Grade IV & $0(0.0)$ & $0(0.0)$ & $0(0.0)$ & $0(0.0)$ & $4(100.0)$ & \\
\hline \multicolumn{7}{|l|}{ 3D merge: } \\
\hline Grade 0 & $50(100.0)$ & $0(0.0)$ & $0(0.0)$ & $0(0.0)$ & $0(0.0)$ & 1.00 \\
\hline Grade I & $0(0.0)$ & $26(100.0)$ & $0(0.0)$ & $0(0.0)$ & $0(0.0)$ & $<0.001$ \\
\hline Grade II & $0(0.0)$ & $0(0.0)$ & $8(100.0)$ & $0(0.0)$ & $0(0.0)$ & \\
\hline Grade III & $0(0.0)$ & $0(0.0)$ & $0(0.0)$ & $19(100.0)$ & $0(0.0)$ & \\
\hline Grade IV & $0(0.0)$ & $0(0.0)$ & $0(0.0)$ & $0(0.0)$ & $4(100.0)$ & \\
\hline
\end{tabular}

Table (2): Sensitivity, specificity, and accuracy for various diagnostic thresholds.

\begin{tabular}{lccccc}
\hline & Sensitivity & Specificity & PPV & NPV & Accuracy \\
\hline T2W1 & 33.0 & 100.0 & 100.0 & 57 & 64 \\
3D MERGE & 100.0 & 100.0 & 100.0 & 100.0 & 100.0 \\
\hline
\end{tabular}



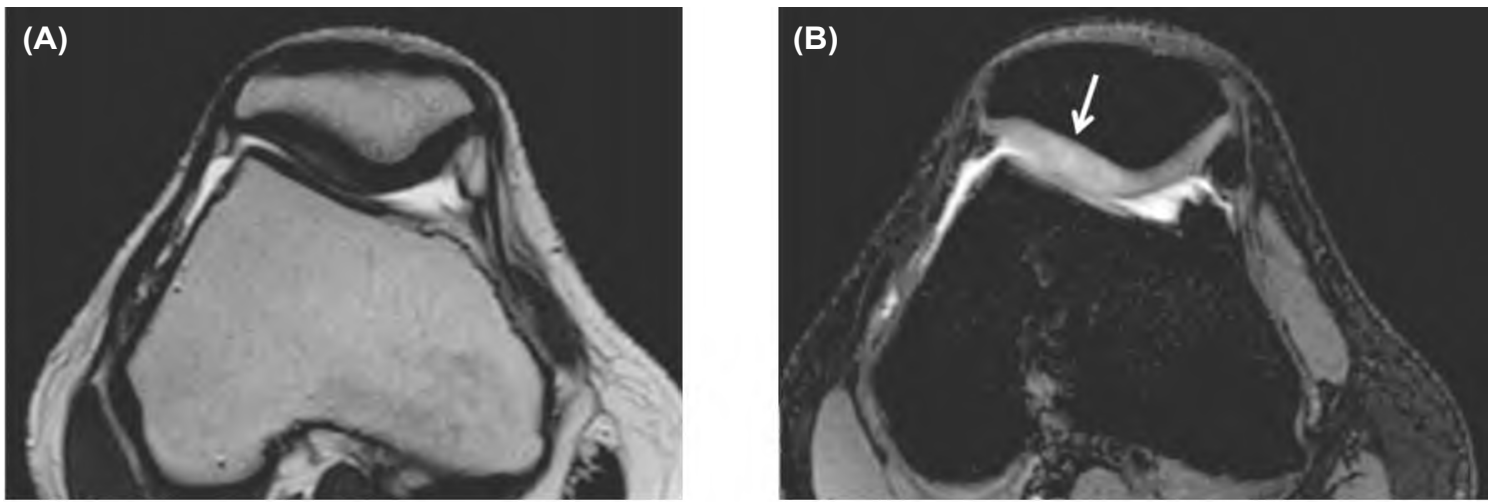

Fig. (1): Grade I cartilage lesion clearly visible in 3D MERGE not detected in T2WI.
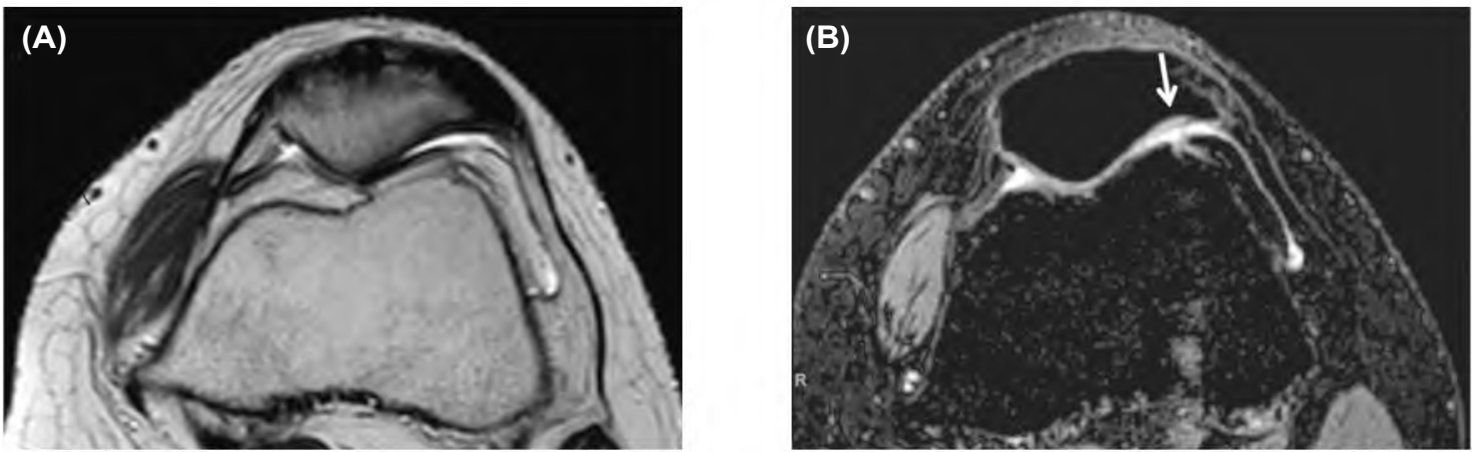

Fig. (2): 3D MERGE show grade 1 cartilage lesion of the medial facet not seen at T2WI.
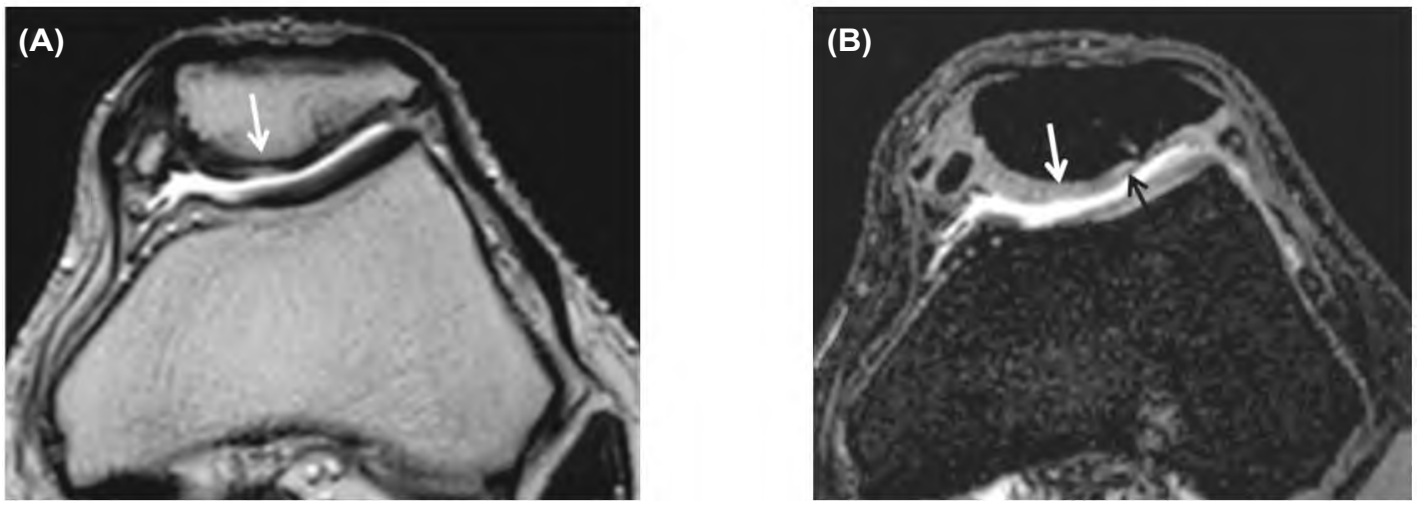

Fig. (3): Cartilage lesion appeared in T2WI as abnormal signal intensity (grade 2) while 3D MERGE partial thickness defect is seen (grade 3) (white arrow). Another area of abnormal signal intensity is seen in 3D MERGE not visible in T2WI. (black arrow).
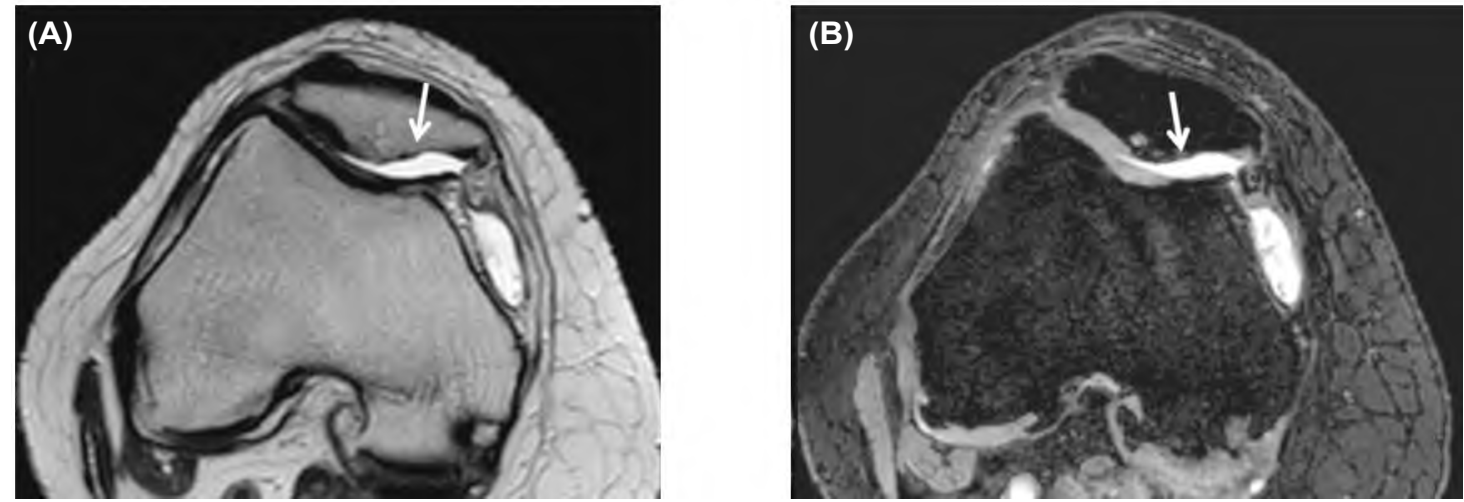

Fig. (4): Grade 4 lesion. Diffuse complete loss of retropatellar cartilage with exposed bone seen in T2WI \& 3D MERGE. 


\section{Discussion}

Early detection of osteoarthritis before the presence of symptoms and radiographic changes is necessary in order to optimize preventive and therapeutic strategies [18].

It was though that the limited efficacy of OA treatment strategies was attributed to the presence of irreversible disease at time of implementation. Therefore, early identification of reversible cartilage changes will enhance treatment effect and slow the disease progression [19].

Radiography is the gold standard for diagnosing OA using the Kellgren-Lawrence (KL) grading system. This system measuring OA severity on a scale of 0 to 4, but it has limitations in assessment of early OA changes involving only cartilages [20,21].

CT arthrography was not routinely used in diagnosis of articular cartilage abnormalities. In a study done by Vande Berg BC et al., [22] they stated that CT arthrography had sensitivity and specificity slightly superior to those of standard MRI (80$88 \%$ vs $78-86 \%$ ) in lesions involving less than half of the cartilage thickness. This method, however, requires an intraarticular contrast injection and is associated with radiation exposure.

Few studies have compared the diagnostic value of standard MRI sequences and MR arthrography in detecting articular cartilage defects in the knee joint. Alparslan et al., [23] stated that the instilled intraarticualr contrast outlines cartilage defects and their contours which increase the image sensitivity to detect cartilage abnormalities.

In a study done by Schmid et al., [16] they find that 2D MEDIC sequence is comparable to the established 3D DESS sequence that has already been described by several authors [24,25]. Kijowki $\mathrm{R}$ and Gold $\mathrm{G}$ [26] stated that 3D DESS sequence allow obtaining high quality multi-planar reformat images following a single acquisition, thereby eliminating the need to repeat sequences with identical tissue contrast in different planes.

In another study done by Disler et al., [27] they found higher sensitivity for cartilage lesion detection in fat-suppressed SPGR images compared to standard spin-echo MRI sequences (75-85\% vs 29 $38 \%$ ). However the specificities of fat-suppressed SPGR and spin-echo sequences were nearly identical about $97 \%$. According to our results, the 3D MERGE sequence had sensitivity similar to that obtained by arthroscope (100\% sensitivity). However standard T2WI had 33\% sensitivity.
Previous study done by Stehling C et al., [28] showed a high prevalence of OA-related cartilage and meniscal abnormalities in middle-aged, asymptomatic individuals. This is in agreement of our study where Low-grade cartilage lesions predominate in asymptomatic patients who are free of OA symptoms and performed MRI examination for other symptoms (64 patients for knee trauma).

Our study population included a larger proportion of low-grade lesions, which are more difficult to detect, however comparison of the MERG sequence with the routinely performed T2WI in relation to surgical grading obtained from arthroscope showed that T2WI had $67 \%$ sensitivity, $64 \%$ overall accuracy, while 3D merge had 100.0 sensitivity, $100.0 \%$ PPV and 100.0 overall accuracy.

Reviewing the literature and comparing our results with arthroscopy we concluded that the 3D MERG sequence is comparable to previously described sequences optimized for cartilage imaging such as the 3D DESS or 3D SPGR sequences with high sensitivity, and excellent specificity in detecting low to intermediate degrees of cartilage defects compared to surgical findings.

\section{Conclusion:}

Adding MERG sequence to routine MRI protocol improved sensitivity for detection of early cartilage lesions within the knee joint. That will allow early diagnosis and management of osteoarthritis and can contribute in decreasing morbidity and complications.

\section{References}

1- LAUREN M., SHAPIRO B.A., EMILY J., et al.: Mechanisms of Osteoarthritis in the Knee: MR Imaging Appearance. J. Magn. Reson. Imaging, 39 (6): 1346-1356, 2014.

2- HUNTER D.J., LO G.H., GALE D., et al.: The reliability of a new scoring system for knee osteoarthritis MRI and the validity of bone marrow lesion assessment: BLOKS (Boston Leeds Osteoarthritis Knee Score). Ann. Rheum. Dis., 67: 206-211, 2008.

3- MARIUS R.S., CHRISTIAN W.A., PETER KOCH, et al.: Imaging of Patellar Cartilage with a 2D MultipleEcho Data Image Combination Sequence. AJR June, 184 (6): 1744-1748, 2005.

4- LUSSE S., CLAASSEN H., GEHRKE T., et al.: Evaluation of water content by spatially resolved transverse relaxation times of human articualar cartilage. J. Magn. Reson. Imaging, 18 (4): 423-430, 2000.

5- PAN J., PIALAT J.B., JOSEPH T., et al.: Knee cartilage $\mathrm{T} 2$ characteristics and evolution in relation to morphologic abnormalities detected at 3-T MR imaging: A longitudinal study of the normal control cohort from the Osteoarthritis Initiative. Radiology, 261 (2): 507-15, 2011. 
6- LINK T.M., STEINBACH LS., GHOSH S., et al.: Osteoarthritis: MR imaging findings in different stages of disease and correlation with clinical findings. Radiology, 226 (2): 373-381, 2003.

7- ECKSTEIN F., HEUDORFER L., FABER S.C., et al.: Long-term and resegmentation precision of quantitative cartilage MR imaging (qMRI). Osteoarthritis and Cartilage, 10 (12): 922-928, 2002.

8- LINK T.M., STAHL R. and WOERTLER K.: Cartilage imaging: Motivation, techniques, current and future significance. Eur. Radiol., 17 (5): 1135-1146, 2007.

9- PAUNIPAGAR B.K. and RASALKAR: Imaging of articular cartilage: Indian J. Radiol. Imaging, 24 (3): 237-248, 2014.

10- CREMA M.D., HUNTER D.J., BURSTEIN D., et al.: Association of changes in delayed gadolinium-enhanced MRI of cartilage (dGEMRIC) with changes in cartilage thickness in the medial tibiofemoral compartment of the knee: A 2 year follow-up study using 3.0 T MRI. Ann. Rheum Dis., 73: 1935-41, 2014.

11- VAN D.P., VANHEVEL F., VANHOENACKER F.M., et al.: Morphological MR imaging of the articular cartilage of the knee at $3 \mathrm{~T}$-comparison of standard and novel 3D sequences. Insights Imaging, 6 (3): 285-93, 2015.

12- DUNN T.C., LU Y., JIN H., et al.: T2 relaxation time of cartilage at MR imaging: Comparison with severity of knee osteoarthritis. Radiology, 232 (2): 592-598, 2004.

13- MOSHER T.J. and DARDZINSKI B.J.: Cartilage MRI T2 relaxation time mapping: Overview and applications. Semin Musculoskelet Radiol., 8 (4): 355-368, 2004.

14- KIM T., MIN B.H. and YOON S.H., et al.: An in vitro comparative study of $\mathrm{T} 2$ and $\mathrm{T} 2 *$ mappings of human articular cartilage at 3-Tesla MRI using histology as the standard of reference. Skeletal Radiol., 43: 947-954, 2014.

15- MARIUS R. SCHMID, CHRISTIAN W.A., PFIRRMANN P., et al.: Imaging of Patellar Cartilage with a 2D MultipleEcho Data Image Combination Sequence. AJR, 184: 17441748,2005

16- FUJINAGA Y., YOSHIOKA H., SAKAI T., SAKAI Y., et al.: Quantitative measurement of femoral condyle cartilage in the knee by MRI: Validation study by multireaders. J. Magn. Reson. Imaging, 39: 972-977, 2014.

17- SCHMID M.R., PFIRRMANN C., KOCH P., et al.: Imaging of Patellar Cartilage with a 2D Multiple-Echo Data Image Combination Sequence. AJR, 184: 1744-1748, 2005.
18- TANAMAS S., WLUKA A., JONES G. and CICUTTINI F.: Imaging of knee osteoarthritis. Therapy, 7 (6): 635$647,2010$.

19- BAY-JENSEN A.C., MADSEN H.S., DAM E., et al.: Which elements are involved in reversible and irreversible cartilage degradation in osteoarthritis? Rheumatol. Int., 30 (4): 435-442, 2010.

20- DEMEHRI S., NEJAD H.N. and CARRINO J.A.: Conventional and novel imaging modalities in osteoarthritis: Current state of the evidence. Curr. Opin. Rheumatol., 27: 295-303, 2015.

21- JOHNSON V.L. and HUNTER D.J.: The epidemiology of osteoarthritis. Best Pract Res. Clin. Rheumatol., 28: 5-15, 2014.

22- BERG V.B., LECOUVET F.E., POILVACHE P., et al.: Assessment of knee cartilage in cadavers with dualdetector spiral CT arthrography and MR imaging. Radiology, 222: 430-436, 2002.

23- ALPARSLAN L., WINALSKI C.S., BOUTIN R.D. and MINAS T.: Postoperative magnetic resonance imaging of articular cartilage repair. Semin Musculoskelet Radiol., 5 (4): 345-63, 2001.

24- MURPHY B.J.: Evaluation of grades 3 and 4 chondromalacia of the knee using $\mathrm{T} 2 *$-weighted $3 \mathrm{D}$ gradient-echo articular cartilage imaging. Skeletal Radiol., 30: 305-311, 2001.

25- MORIYA S., MIKI Y., YOKOBAYASHI T. and ISHIKAWA M.: Three-dimensional double-echo steadystate (3D-DESS) magnetic resonance imaging of the knee: Contrast optimization by adjusting flip angle. Acta. Radiol., 50 (5): 507-11, 2009.

26- KIJOWKI R. and GOLD G.: Routine three-dimensional magnetic resonance imaging of joints. J. Magn. Reson. Imaging. Apr., 33 (4): 758-771, 2011.

27- PALOSAARI K., OJALA R., SEQUEIROS R.B. and TERVONEN O.: Fat Suppression Gradient-Echo Magnetic Resonance Imaging of Experimental Articular Cartilage Lesions: Comparison Between Phase Contrast Method at $0.23 \mathrm{~T}$ and Chemical Shift Selective Method at 1.5T. J. Magn. Reson. Imaging, 18: 225-231, 2003.

28- STEHLING C., LIEBL H., KRUG R., et al.: Patellar cartilage: $\mathrm{T} 2$ values and morphologic abnormalities at 3.0-T MR imaging in relation to physical activity in asymptomatic subjects from the osteoarthritis initiative. Radiology, 254 (2): 509-520, 2010. 


\section{إختبار إضافة T2 MERGE إلى البروتوكول الروتينى إلروين

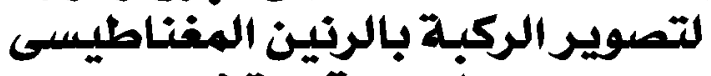

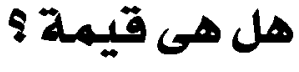

خشونة المفاصل هى سبب رئيسى للإعاقة عند كبار السن ولها آثار كبيرة على الصحة العامة.

يعد الاكتشاف المبكر أمراً بالغ الأهمية لفهم تطود المرض حيث أثه يساهم في تطوير استراتيجيات العلاج مما يساعد على إيقاف المرض أو إبطاء تقدمه .

يتميز التصوير بالرنين المغناطيسى على قدرته على تصوير الأنسجة الرخوة مثل الفضاريف بتباين عالى وقد حسنت التقنيات المتقدمة من قدرته على تقييم شكل الفضروف والتغين النغيرات الجزيئية التى تحدث فيه.

تهدف هذه الدراسة إلى إختبار قيمة إضافة T2 MERGE إلى البروتوكول الروتينى لتصوير الركبة بالرنين المغناطيسى للكثف المبكر عن تغيرات الغضاريف حول الركبة.

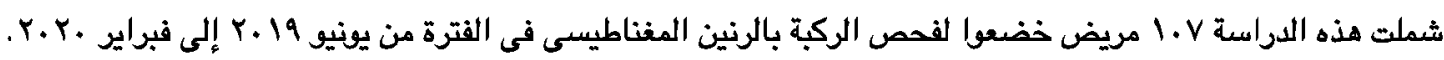

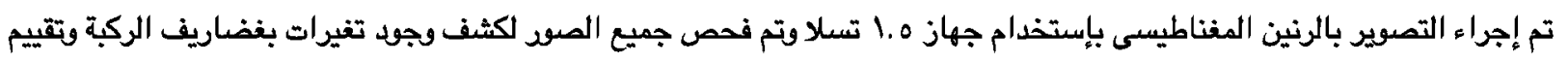

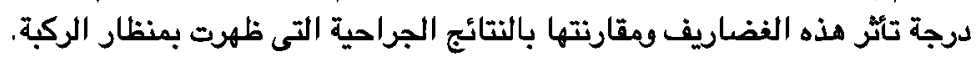
MERGE أظهر تحليل البيانات بإستخدام التحليل الإحصائى تطابق كلى بين نتائج المنظار الجراحى وصور فحص الرنين بإستخدام

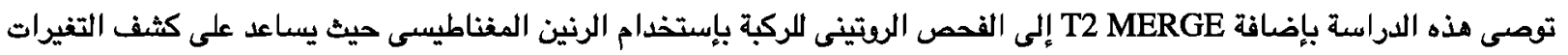

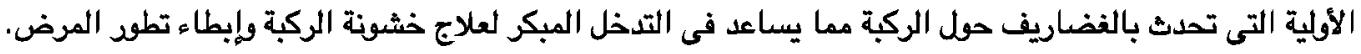

